\title{
Resenha
}

\section{Helena Antipoff: uma biografia intelectual}

\author{
Helena Antipoff: an intellectual biography
}

\section{Helena Antipoff: una biografía intelectual}

\author{
Deolinda Armani Turci \\ Universidade Federal de Minas Gerais - MG \\ Larissa Assunção Rodrigues \\ Universidade Federal de Minas Gerais - MG \\ Érika Lourenço \\ Universidade Federal de Minas Gerais - MG
}

CAMPOS, R. H. de F. (2012). Helena Antipoff: psicóloga e educadora: uma biografia intelectual. Rio de Janeiro: Fundação Miguel de Cervantes, 451p.

Helena Antipoff, russa radicada no Brasil, pode ser considerada um marco na educação e na psicologia brasileiras. Suas contribuições tiveram grande impacto na educação infantil e na formação de docentes a partir da década de 1930, principalmente em Minas Gerais.

Regina Helena de Freitas Campos, pesquisadora e professora da Faculdade de Educação da Universidade Federal de Minas Gerais, vem nos brindando com várias produções que descortinam o universo de Antipoff. A obra que ora apresentamos é mais uma produção de Campos e faz parte da Coleção Memória do Saber. A Coleção, produzida numa parceria entre o Ministério da Cultura do Brasil, o CNPq e a Fundação Miguel de Cervantes, tem por objetivo disponibilizar para o público, documentos que comprovam a grandiosidade da produção científica, pensamento social, do ensino e da pesquisa brasileiros.

O livro está organizado da seguinte forma: "Introdução", "Parte I - Teoria, método e contexto", "Parte II - Trajetória de Helena Antipoff - a construção da perspectiva sociocultural em psicologia e educação", "Lições para o futuro", "Cronologia: vida e obra de Helena Antipoff".

A trajetória de Campos como pesquisadora é focalizada na "Introdução" e nos permite perceber como, em sua história, vida e obra de Helena Antipoff foram se constituindo como objetos de pesquisa.

A parte do livro denominada "Teoria, método e contexto" é composta por três capítulos: "Perspectivas históricas e teóricas", "Método" e "O contexto: o movimento de renovação escolar e de desenvolvimento das ciências da educação na Europa, América do Norte, União Soviética e Brasil”.

No capítulo "Perspectivas históricas e teóricas" a autora demonstra a necessidade de compreender os estudos sociológicos e psicológicos acerca das características da natureza humana que influenciaram a abordagem sociocultural de Antipoff. Apresenta, dentre outras, a perspectiva sociológica de Durkheim e a perspectiva psicossocial de Vygotsky. Retrata que diversos psicólogos elaboraram estudos a partir de conceitos de representações definido por Durkheim com o objetivo de criar um processo que viabilize a investigação dos fatos pertinentes à construção social do psiquismo. Quanto a Vygotsky, enfatiza sua proposta de que a "cultura é o produto, ao mesmo tempo, da vida social e da atividade social do homem" (p.47).

O capítulo "Método" trata do método de pesquisa utilizado para a composição da biografia intelectual de Helena Antipoff. Ressalta a relevância da biografia para o estudo da 
história da ciência e a necessidade de se levar em conta o contexto sociocultural, político e intelectual das produções dos autores investigados.

No capítulo "O contexto: o movimento de renovação escolar e de desenvolvimento das ciências da educação na Europa, América do Norte, União Soviética e Brasil”, Campos relata o contexto de formação de Antipoff. Apresenta o movimento de renovação escolar da Escola Nova, bem como o desenvolvimento das ciências da educação a partir do final do século XIX na Europa, América do Norte, União Soviética e Brasil. Destaca teorias que no início do século $\mathrm{XX}$ foram fundamentais na constituição do pensamento antipoffiano, tais como a psicologia funcional de Claparède (Suíça); os estudos sobre a estrutura psíquica de Freud (Áustria); os estudos sobre inteligência de Binet (França); as publicações sobre a psicologia da criança, de Stanley Hall e Dewey (Estados Unidos), e a Psicologia Pedagógica russa de Vygotski (União Soviética).

Sobre a realidade brasileira nas primeiras décadas do século $X X$, a autora aborda a questão das altas taxas de repetência e evasão escolar nas escolas públicas e a preocupação com a formação de professores, destacando o desenvolvimento da Psicologia Aplicada.

Sob o título "Trajetória de Helena Antipoff - a construção da perspectiva sociocultural em psicologia e educação", a segunda parte do livro também se divide em três capítulos: "Formação e primeiras experiências profissionais na Europa", "Conhecendo as crianças e adolescentes brasileiros" e "Teoria e prática da educação: propondo novas alternativas, criando instituições".

O capítulo "Formação e primeiras experiências profissionais na Europa" trata dos primeiros anos da história de vida de Antipoff, suas origens na Rússia, sua formação intelectual, seus estudos e primeiras experiências profissionais. Campos ressalta a importância de sua formação na Sorbonne, onde, sob a influência das ideias de Binet, interessou-se pela Psicologia e por sua relação com a Pedagogia, e em Genebra, no Instituto Jean Jacques Rousseau, onde conduziu investigações com foco no desenvolvimento da inteligência na criança, na relação entre processos psicológicos superiores e motricidade, e no julgamento moral.

O trabalho na Rússia agregou à formação de Antipoff uma experiência fundamental para o trabalho que posteriormente desenvolveria no Brasil. Familiarizou-se com o Método da Experimentação Natural de Lazurski, que permitia a avaliação da inteligência e da personalidade da criança a partir da observação de seu desempenho na realização de atividades cotidianas, uma alternativa às situações artificiais de avaliação psicológica através de provas aplicadas em laboratórios.

Um panorama geral da educação brasileira, o processo de implantação da Escola de Aperfeiçoamento de Belo Horizonte e o trabalho de Antipoff nesta são descritos no capítulo "Conhecendo as crianças e adolescentes brasileiros". Na oportunidade a autora nos transporta a 1929 e às pesquisas sobre as crianças mineiras que Antipoff desenvolveu com a ajuda de suas alunas. A pesquisa dos "Ideais e Interesses das crianças de Belo Horizonte" foi a primeira a ser proposta por Antipoff no Brasil. Com ela, a psicóloga desejava orientar-se sobre a psicologia das crianças brasileiras, conhecer a educação por elas recebida e o tipo de ambiente social em que viviam.

A concepção de Antipoff sobre inteligência é também enfatizada neste capítulo. Ela não concordava com uma visão puramente inatista da inteligência. Em sua opinião, seria a inteligência civilizada, isto é, a capacidade de conhecimento polida pela ação da sociedade, que seria medida pelos testes ditos de inteligência.

Este capítulo do livro é bastante denso e evidencia os esforços de Antipoff em proceder a uma nova perspectiva em relação ao papel da escola: desenvolver as capacidades intelectuais e as aptidões das crianças, e não apenas transmitir conhecimentos, individualizar o ensino. Para tanto, desenvolveu métodos e propôs modelos para a educação. Defendia que o educador deveria ter uma formação científica sólida para dar conta do seu trabalho, que exigiria ao mesmo tempo criatividade, reflexão e método.

Observa-se com a leitura do capítulo "Teoria e prática da educação: propondo alternativas, criando instituições", que Antipoff tinha preocupação crucial com as crianças que necessitavam de atendimentos educativos especiais. Fundou em 1932 a Sociedade Pestalozzi de Belo Horizonte, que deveria contribuir para a educação das crianças com deficiência. A partir dessa instituição criou em 1935, o Instituto Pestalozzi de Belo Horizonte, dedicado ao exame, educação e tratamento de crianças com deficiências. Para Antipoff, a escola especial não deveria romper os vínculos com a escola regular, em uma perspectiva semelhante ao que atualmente se denomina educação inclusiva. A ideia era que, longe de isolar os excepcionais, era preciso trazê-los ao convívio com a comunidade, utilizando a recreação, o jogo e o trabalho criativo como procedimentos de integração ao grupo e à comunidade.

Também são expostas neste capítulo as vivências de Antipoff na Fazenda do Rosário, complexo educacional que atendia também a crianças da área rural e promovia cursos para a formação de professores, entre outras atividades.

Muito interessante é o estudo comparativo que Campos faz entre as propostas antipoffianas e a teoria sociocultural de Vygotski. A autora pormenoriza as atuações e entendimentos de Antipoff sobre educação e desenvolvimento humano, ao mesmo tempo em que evidencia as aproximações e os contrastes dos mesmos com a teoria sociocultural.

Uma exposição do que se pretendeu com o livro e os princípios da educação ideal para Antipoff, expandindo o conhecimento público sobre a obra dessa escritora podem ser observados no capítulo denominado "Lições para o futuro". Campos ressalta que as contribuições da psicóloga foram profícuas para o desenvolvimento de uma perspectiva sociocultural.

Uma "Cronologia: vida e obra de Helena Antipoff (1892-1974)" é o último capítulo da obra. Neste capítulo Campos apresenta, em ordem cronológica e resumidamente, os principais eventos e feitos de Antipoff. 
Finalizando, pode-se dizer que o livro aqui apresentado é uma obra de valor inestimável, não só para os estudiosos das ciências humanas brasileiros, mas para os pesquisadores e educadores do mundo inteiro. O relato vai muito além da simples descrição da biografia e dos estudos de Antipoff, focando os aspectos mais importantes das indagações e dos avanços científicos conquistados por ela. A partir de sua leitura, o público se sente convidado a explorar mais as propostas teóricas e práticas da psicóloga e educadora Helena Antipoff.

Recebido em: 19/10/2013

Aprovado em: 17/12/2013

\section{Sobre as autoras}

Deolinda Armani Turci (deoarmani@gmail.com)

Curso de Psicologia - Faculdades Pitágoras BH

Mestre em Educação (Wisconsin University Extention) - Mestrando em Psicologia (Fafich-Universidade Federal de Minas Gerais)

Larissa Assunção Rodrigues (larissarodrigues@fafich.ufmg.br)

Departamento de Psicologia - Universidade Federal de Minas Gerais

Mestre em Psicologia Social (UFMG) - Doutoranda em Educação (FaE-Universidade Federal de Minas Gerais)

Érika Lourenço (erikalourenco.mail@gmail.com)

Departamento de Psicologia - Universidade Federal de Minas Gerais

Mestre em Psicologia Social (Programa de Pós Graduação em Psicologia - Universidade Federal de Minas Gerais) e Doutora em Educação (Faculdade de Educação - Universidade Federal de Minas Gerais) 